\title{
The Risk-return Trade-off in Emerging Stock Markets: Evidence from Saudi Arabia and Egypt
}

\author{
Suliman Zakaria Suliman Abdalla \\ Correspondence: Suliman Zakaria Suliman Abdalla, Assistant Professor, Department of Quantitative Analysis, \\ College of Business Administration, King Saud University, Riyadh, Kingdom of Saudi Arabia. Tel: 96-65-6084-7037. \\ E-mail: sulabdalla@ksu.edu.sa
}

$\begin{array}{lcc}\text { Received: April 1, } 2012 & \text { Accepted: May 2, } 2012 & \text { Published: June 1, } 2012 \\ \text { doi:10.5539/ijef.v4n6p11 } & \text { URL: http://dx.doi.org/10.5539/ijef.v4n6p11 }\end{array}$

\begin{abstract}
This paper examines empirically the trade-off between risk (conditional volatility) and expected returns for the Saudi Arabian and Egyptian stock indices over the period of January 1, 2007 to December 30, 2011. The empirical analysis of the paper is carried out by means of the generalized autoregressive conditional heteroscedastic $(\mathrm{GARCH})$ in mean methodology including both symmetric (GARCH-M) and asymmetric (EGARCH-M) models. The results show that the dynamic risk-return relationship is quite different between Saudi Arabian and Egyptian stock markets. A negative but insignificant relationship between expected returns and conditional volatility is found for daily returns in Egypt. In contrast, the conditional mean of the stock returns is positively but insignificantly related to its conditional variance in Saudi stock market a result which is consistent with the theory of a positive risk premium on stock indices which states that higher returns are expected for assets with higher level of risk. The findings of the paper are useful for financial decision making.
\end{abstract}

Keywords: expected returns, conditional volatility, trade-off, GARCH-in-mean model

\section{Introduction}

The relationship between stock market returns and their own conditional volatility (as a proxy for risk) (Note 1) has been extensively investigated in empirical finance literature during the last few years. A clear understanding of this relationship can be considered as one of the most important variables for investors as well as policy makers as it affects expected rates of return on every existing asset investment, for example it can help individual investors to make some predictions about the future and therefore, affects their investment decision making. It can also be regarded as an essential part for many financial applications and key components for example to mean-variance portfolio theory and for different asset pricing models.

In Econometrics practice, it is a well known fact that financial market volatility is not directly observable and that financial returns volatility exhibits certain characteristics that are specific to financial time series such as volatility clustering (Note 2) and leverage effect (Note 3) (Bollerslev, 1986). To estimate and therefore, capture these characteristics, financial econometricians have developed a variety of time-varying volatility models, among them, the autoregressive conditional heteroscedastic (Note 4) (ARCH) model proposed by Engle (1982) and its extension; generalized autoregressive conditional heteroscedastic (GARCH) model developed independently by Bollerslev (1986), and Taylor (1986) are well-known and frequently applied models. This development of econometric techniques leads financial economists and practitioners to rethink on traditional econometric methods (such as ordinary least squares, OLS) and also leads to creation of new versions of ARCH/GARCH framework such as GARCH-in-mean model (GARCH-M), Exponential GARCH-in-mean model (EGARCH-M), Threshold GARCH-in-mean model (TGARCH-M) and Power-in-mean GARCH model (PGARCH-M). These models can be used effectively to model and investigate the risk-return trade-off in financial markets, see for example (Bali and Peng, 2006; French et al., 1987; Ghyselsa et al., 2005; Glosten et al., 1993; Guo \& Whitelaw, 2006; and Harrison \& Zhang, 1999)

In Finance theory, it is generally accepted that the expected return of the market is positively and proportionally related to the conditional volatility meaning that if there are expectations of higher levels of risk associated with a particular investment then greater returns are required as compensation for that higher expected risk (Note5). Alternatively, if an investment has relatively lower levels of expected risk then investors are satisfied with relatively lower returns (Note 6). For example, the intertemporal capital asset pricing model (ICAPM) of Merton (1973) predicts a positive times series relation between the conditional mean and variance of market returns (Note 7). However, the 
existing empirical evidence on the time series risk and return has drawn conflicting conclusions. For example Bansal and Lundblad (2002), Campbell and Hentschel (1992), Chou (1988), and French et al. (1987), Ghysels et al. (2005) and Ludvigson and $\mathrm{Ng}$ (2007) find the expected return positively related to its conditional variance. On the other hand, Bekaert and Wu (2000), Breen et al. (1989), Campbell (1987), Fama and Schwert (1977), Glosten et al. (1993), and Nelson (1991) all report a negative relationship between expected returns and conditional volatility.

More recently the issue of risk-return tradeoff is extensively investigated, for example Hibbert et al. (2008) found negative asymmetric return-volatility relation for the S\&P 500 index returns. Hatemi-J \& Irandoust (2011) also supported the negative relationship between returns and volatility for the US stock market. Feunou et al. (2010) show that the risk-return relationship is nonlinear, time-varying, and crucially depends on the dynamics of conditional skewness of returns. Yakob and Sarath Delpachitra (2006) and Leon et al. (2007) found a positive relationship between conditional excess returns and conditional variance.

Although there is much literature on the dynamic relationship between risk and returns of developed stock markets in industrialized countries, there is a lack of similar studies for emerging stock markets, especially for Arab stock markets ( To the best of my knowledge). Thus, one of the contributions of this paper is to provide empirical evidence on this relationship in two largest markets in the Arab world.

The main purpose of this paper is to investigate the relationship between stock market returns and their own volatility to see the existence of a time-varying risk premium in the Saudi Arabian and Egyptian stock markets. The paper applies both the GARCH-M and the EGARCH-M models to check for symmetric and asymmetric (bad and good news) impact of stock price volatility on the expected returns. The remainder of the paper is proceeds as follows: Section 2 gives an overview of the stock market in Saudi Arabia and Egypt. Section 3 presents the data and Section 4 gives a brief review of empirical methodology used. In section 5, the empirical results will be provided and finally, Section 6 concludes the paper.

\section{Overview of Stock Market in Saudi Arabia and Egypt}

\subsection{Saudi Stock Market}

The Saudi stock exchange (SSE) existence dates back to 1970s when it used to operate informally. In 1984, a Ministerial Committee comprising Ministry of Finance, Ministry of Commerce and SAMA (Note 8) was formed to regulate the market. SSE which is known locally by its Arabic name Tadawul. The Saudi stock market has several unique characteristics that differentiate it from other stock markets in the world. Share-trading activity is executed through commercial banks that are responsible for the settlement of transactions between buyers and sellers. The market is also characterized by the absence of a bourse and independent market-makers.

The overall performance of the Saudi stock market is measured by the Tadawul All Share Index (TASI) (Note 9), TASI reached its peak on $25^{\text {th }}$ of February 2006, when it closed at 20,635. It was severely affected by the 2008 global crisis, like all the stock markets all over the world, and saw below 4000.

The Saudi stock market currently lists 144 publicly traded companies divided into fifteen sectors (as of August 15, 2010), Financials and Basic Materials sectors are the dominant sectors, together accounting for around $70 \%$ of market capitalization. The biggest two companies by market share are Al RAJHI Bank and SABIC, a petrochemical producer, both of which command around $11 \%$ of the market. The trading activity of the Saudi stock market can be considered very active with respect to the value of shares traded, the number of executed transactions and market capitalization (See Table 1) which suggests an increase in investor confidence during this time period.

Today, Saudi Stock market is the largest market in the entire Arab World. Based on market capitalization, the Saudi stock market ranks first in the Arab world with 319 billion U.S. dollars compared to an average of 65 billion dollars for the Arab countries participating in the Arab Monetary Fund Index (AMFI). Compared to the other Arab stock markets in the AMFI, the Saudi stock market had by far the largest market, with its value of shares traded amounting to 337 U.S. billion dollars in 2009 (Table 2). The second largest stock market is the Kuwaiti stock market, at 104 billion U.S. dollars. Additionally, the Saudi stock market is active and relatively liquid compared to the other markets in the AMFI as measured by market depth ratio and the turnover ratio respectively. At the end of 2009, the depth of the Saudi Stock Market was $86 \%$ of GDP compared to an average of 57\% of GDP for Arab share markets, and was one of the most liquid markets in the Arab world with a turnover ratio of $106 \%$ compared to an average of $54 \%$ for Arab share markets in 2009 (Table 2).

\subsection{Egyptian Stock Market}

In contrast to the SSE, the Egyptian exchange is one of the oldest stock markets established in the Middle East and Africa. Egypt's stock exchange has two locations: the main location is in Cairo (established 1903) and the other one is in Alexandria established (1883).These two exchanges were competing with each other before they merged in recent 
years. Today, both exchanges are governed by the same chairman and board of directors. They are commonly referred to as the Cairo and Alexandria Stock Exchange (CASE) and share the same trading, clearing and settlement systems, so that market participants have access to stocks listed on both exchanges.

The overall performance of the Egyptian stock market is measured by the Capital Market Authority (CMA) Index, which covers all listed stocks weighted in relation to their market capitalization. It can be viewed as an all share index that covers the broadest base of stocks. It is calculated and released daily by the CMA (Note 10).

\subsection{Key Numbers of the TADAWUL and CASE}

Table 1 provides some key figures for both markets. It is obvious that although CASE has relatively large number of listed companies, TADAWUL has a larger market capitalization, volume of trading, number of transactions and number of shares traded during the period of the study.

Table 1. Summary of Trading Activity in TADAWUL and CASE, 2007 - 2011

\begin{tabular}{lccccc}
\hline Year & Listed Companies & $\begin{array}{c}\text { Value Traded } \\
\text { (\$ millions) }\end{array}$ & $\begin{array}{c}\text { Market Capitalization } \\
\text { (\$ millions) }\end{array}$ & $\begin{array}{c}\text { No. of } \\
\text { Transactions }\end{array}$ & $\begin{array}{c}\text { Shares } \\
\text { Traded } \\
\text { (In Million) }\end{array}$ \\
\hline \multicolumn{2}{l}{ Saudi Stock Market (TADAWUL) } & & & & \\
\hline 2007 & 111 & $628,055.57$ & $522,721.12$ & 11343727 & $53,083.03$ \\
2008 & 127 & $483,122.22$ & $246,809.85$ & 11082545 & $54,441.98$ \\
2009 & 135 & $322,432.10$ & $318,784.68$ & 12197799 & $54,443.71$ \\
2010 & 146 & $192,445.39$ & $353,419.01$ & 16108992 & $31,555.34$ \\
2011 & 144 & $247,143.91$ & $328,029.67$ & 10356812 & $40,995.49$ \\
\hline Egypt Stock Market (CASE) & & & & \\
\hline 2007 & 435 & $49,388.19$ & $134,903.52$ & $8,161,607$ & $10,512.79$ \\
2008 & 373 & $65,166.14$ & $83,185.00$ & $12,321,523$ & $21,071.82$ \\
2009 & 306 & $50,812.70$ & $86,267.22$ & $13,300,653$ & $28,243.25$ \\
2010 & 212 & $36,867.80$ & $85,725.96$ & $9,606,668$ & $27,336.99$ \\
2011 & 213 & $18,081.29$ & $48,679.23$ & 5439868 & $16,669.04$ \\
\hline
\end{tabular}

Source: Compiled by the author based on data from the Tadawul website and AMF annual reports.

Table 2. Key Indicators of Arab World Share Markets, End of 2009

\begin{tabular}{|c|c|c|c|c|c|c|}
\hline $\begin{array}{l}\text { Capital } \\
\text { Market }\end{array}$ & $\begin{array}{c}\text { No. of Listed } \\
\text { Companies }\end{array}$ & $\begin{array}{c}\text { Market* } \\
\text { Capitalization }\end{array}$ & $\begin{array}{c}\text { Ratio to Total } \\
(\%)\end{array}$ & $\begin{array}{c}\text { Value of Shares } \\
\text { Traded* }\end{array}$ & $\begin{array}{l}\text { Market } \\
\text { Depth }\end{array}$ & $\begin{array}{c}\text { Turnover } \\
\text { Ratio }\end{array}$ \\
\hline Saudi Arabia & 135 & 318,803 & 35.29 & 337.070 & 86.3 & 105.7 \\
\hline Kuwait & 205 & 93,824 & 10.38 & 103.772 & 73.5 & 110.6 \\
\hline Egypt & 306 & 91,092 & 10.8 & 81.173 & 48.1 & 89.1 \\
\hline Qatar & 44 & 87,930 & 9.73 & 25.317 & 106.8 & 28.8 \\
\hline Abu Dhabi & 67 & 80,201 & 8.88 & 18.766 & 35.7 & 23.4 \\
\hline Morocco & 73 & 74,186 & 8.21 & 16.226 & 80.0 & 21.9 \\
\hline Dubai & 67 & 58,095 & 6.43 & 47.239 & 25.8 & 81.3 \\
\hline Jordan & 272 & 31,889 & 3.53 & 13.641 & 105.8 & 42.8 \\
\hline Oman & 120 & 23,616 & 2.61 & 5.905 & 44.5 & 25.0 \\
\hline Bahrain & 49 & 16,263 & 1.80 & 473.0 & 75.2 & 2.9 \\
\hline Lebanon & 11 & 12,843 & 1.42 & 1.038 & 39.9 & 8.1 \\
\hline Tunisia & 52 & 9,237 & 1.02 & 1.360 & 24.5 & 14.7 \\
\hline Sudan & 53 & 3,033 & 0.34 & 1.006 & 5.5 & 33.2 \\
\hline Palestine & 39 & 2,377 & 0.26 & 500.0 & $\mathrm{Na}$. & 21.0 \\
\hline Algeria & 2 & 91 & 0.01 & 187.5 & 0.1 & 206.1 \\
\hline
\end{tabular}

* Million of U.S. dollars.

Source: Quarterly Bulletin, Arab Monetary Fund, 2009.

\section{The Data and Basic Statistics}

\subsection{Data for Analysis}

The time series data used for investigating the risk-return relationship in this paper are the daily closing prices of the 
Saudi Stock Market (SSM) index and the Capital Market Authority (CMA) index over the period from $1^{\text {st }}$ January 2007 to $30^{\text {th }}$ December 2011. Anderson and Bollerslev (1998) argue that the use of high frequency data (Like daily observations) is desirable to uncover the risk-return relationship. This is because it allows for a better measurement of risk and enables precise identification of the risk-return trade-off. This is because high frequency data produces better estimates of conditional volatility process. The closing prices of the two markets have been taken from the SSM website (http://www.tadawul.com.sa) and the CASE website (http://www.egyptse.com).

Daily returns $r_{t}$ were calculated as the continuously compounded returns corresponding to the first difference in logarithms of closing prices of successive days:

$$
r_{t}=\log \left(\frac{P_{t}}{P_{t-1}}\right)
$$

where $P_{t}$ and $P_{t-1}$ denote the closing market index of SSM and CASE at the current ( $\left.\mathrm{t}\right)$ and previous day (t-1), respectively.

\subsection{Summary Statistics}

To specify the distributional properties of the daily returns series in Tadawul and CASE markets during the period of this study, some descriptive statistics are reported in Table 3.

Table 3. Descriptive Statistics of the Tadawul and CASE Return Series

\begin{tabular}{lcc}
\hline Statistics & Tadawul Index Returns & CMA Index Returns \\
\hline Mean & -0.000199 & -0.001028 \\
Maximum & 0.090874 & 0.271107 \\
Minimum & -0.103285 & -0.515104 \\
Standard Deviation & 0.016795 & 0.028288 \\
Skewness & -0.797523 & -5.152991 \\
Kurtosis & 10.53532 & 106.0035 \\
Jarque-Bera & $3223.334^{*}$ & $582232.4^{*}$ \\
No. of observation & 1304 & 1288 \\
\hline
\end{tabular}

Note: * denotes statistical significance at $1 \%$ level.

As can be seen from Table 3, the average return is negative in both markets. The distribution of returns differs markedly from normality given the observed skewness and excess kurtosis. Consequently, based on the Jarque-Bera (J-B) statistic, the null hypothesis of normality for the daily Tadawul and CMA returns has to be rejected at the $1 \%$ significance level. Moreover, Figures 1 and 2 present the pattern of the price index series and its returns for the Tadawul and the CMA during the study period.

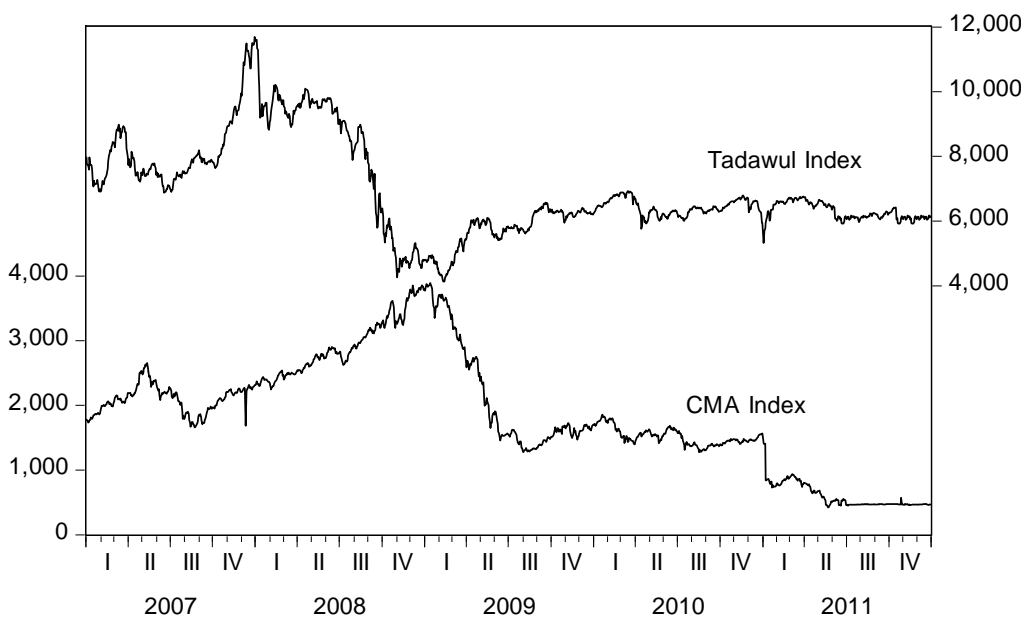

Figure 1. Tadawul and CMA Indices (January 2007 - December 2011) 


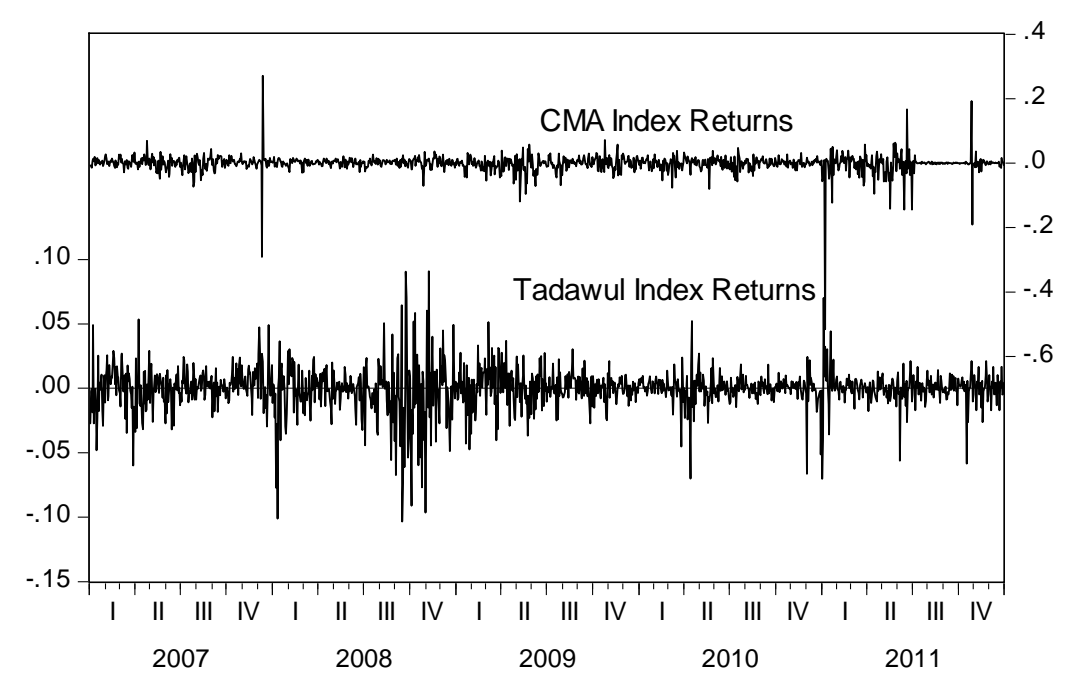

Figure 2. Returns of Tadawul and CMA Indices (January 2007 - December 2011)

\subsection{Testing for Heteroscedasticity}

One of the most important issues before applying the generalized autoregressive conditional heteroscedastic (GARCH) methodology is to first examine the residuals for evidence of heteroscedasticity. To test for the presence of heteroscedasticity in the residuals of the returns series, the Lagrange Multiplier (LM) test proposed by Engle (1982) is applied.

In summary, the test procedure is performed by first obtaining the residuals $e_{t}$ from the ordinary least squares regression of the conditional mean equation which might be an autoregressive (AR) process, moving average (MA) process or a combination of AR and MA processes, i.e. ARMA process. For example, in the ARMA $(1,1)$ process the conditional mean equation will be:

$$
r_{t}=\phi_{1} r_{t-1}+\varepsilon_{t}+\theta_{1} \varepsilon_{t-1}
$$

After obtaining the residuals $e_{t}$, the next step is to regress the squared residuals on a constant and q lags as in the following equation:

$$
e_{t}^{2}=\alpha_{0}+\alpha_{1} e_{t-1}^{2}+\alpha_{2} e_{t-2}^{2}+\ldots+\alpha_{q} e_{t-q}^{2}+v_{t}
$$

The null hypothesis that there is no autoregressive conditional heteroscedasticity (ARCH) up to order q can be formulated as:

$$
H_{0}: \alpha_{1}=\alpha_{2} .=\alpha_{q}=0
$$

against the alternative:

$$
H_{1}: \alpha_{i}>0
$$

for at least one $i=1,2, \ldots, q$.

The test statistic for the joint significance of the q-lagged squared residuals is given by the number of observations times the R-squared $\left(T R^{2}\right.$ ) of the regression (3). $T R^{2}$ is evaluated against the $\chi^{2}(q)$ distribution. This represents an asymptotically locally most powerful test (Rachev et al., 2007).

In this paper, first, an autoregressive moving average ARMA $(1,1)$ model is employed for the conditional mean in the returns series as an initial regression, then, the null hypothesis that there are no ARCH effects in the residual series is tested up to lag 30 corresponding to one trading month. The results of this examination are summarized in Table 4. 
Table 4. ARCH-LM Test for residuals of returns on the Tadawul and CMA market

\begin{tabular}{lrr}
\hline \multicolumn{3}{c}{ ARCH-LM test statistic } \\
\hline Lags & Tadawul Index Returns & CMA Index Returns \\
\hline 5 & $275.9787^{*}$ & $37.434^{*}$ \\
10 & $291.8388^{*}$ & $39.321^{*}$ \\
15 & $316.7501^{*}$ & $40.446^{*}$ \\
20 & $329.3702^{*}$ & $44.128^{*}$ \\
25 & $339.4804^{*}$ & $47.387^{*}$ \\
30 & $341.2769^{*}$ & $49.272^{*}$ \\
\hline
\end{tabular}

Note: $*$ denotes statistical significance at $1 \%$ level.

The ARCH-LM test results in Table 4 provide strong evidence for rejecting the null hypothesis for all lags included. Rejecting $H_{0}$ is an indication of the existence of ARCH effects in the residuals series of the mean equation and therefore the variance of the returns series of Tadawul and CASE indices are non-constant.

\section{Econometric Methodology}

The empirical investigation of this paper is conducted by means of the generalized autoregressive conditional heteroscedastic approach including both symmetric $(\operatorname{GARCH}(1,1)-\mathrm{M})$ and asymmetric $(\operatorname{EGARCH}(1,1)-\mathrm{M})$ models (Note 11) that capture most common stylized facts about index returns such as volatility clustering and leverage effect. The main reason to use GARCH framework lies in the fact that a conditional stochastic process generates the return data with a changing variance. Therefore, it is naturally expected that GARCH is the right tool to approach to the problem since it takes the changing variances into consideration. This GARCH specification is often interpreted in a financial context, where an agent or trader predicts this period's variance by forming a weighted average of a long term average (the constant), the forecast variance from last period (the GARCH term), and information about volatility observed in the previous period (the $\mathrm{ARCH}$ term). If the asset return was unexpectedly large in either the upward or the downward direction, then the trader will increase the estimate of the variance for the next period. In presenting these models, there are two distinct specifications, the first for the conditional mean and the other for the conditional variance. The models paper are estimated using maximum likelihood method as in Bollerslev and Wooldridge (1992) (Note 12) under the assumption of Gaussian normal distribution. The log likelihood function is maximized using Marquardt numerical iterative algorithm to search for optimal parameters.

\subsection{The Generalized Autoregressive Conditional Heteroscedastic in Mean (GARCH-M) Model}

In finance, the return of a security may depend on its volatility. To model such a phenomenon one may consider the GARCH-M model (Note 13) of Engle, Lilien, and Robins (1987), where "M" stands for "in mean". This model is an extension of the basic GARCH framework which allows the conditional mean of a sequence to depend on its conditional variance or standard deviation. In this paper, the following simple specification GARCH $(1,1)-\mathrm{M}$ is used:

$$
\begin{array}{cl}
\text { Mean equation } & r_{t}=\mu+\lambda \sigma_{t}^{2}+\varepsilon_{t} \\
\text { Variance equation } & \sigma_{t}^{2}=\omega+\alpha \varepsilon_{t-1}^{2}+\beta \sigma_{t-1}^{2}
\end{array}
$$

where $\omega>0, \quad \alpha_{1} \geq 0$ and $\beta_{1} \geq 0$, and

$r_{t}=$ return of the asset at time $\mathrm{t}$,

$\mu$ = average return,

$\varepsilon_{t}=$ residual returns, defined as:

$$
\varepsilon_{t}=\sigma_{t} z_{t}
$$

where $z_{t}$ is standardized residual returns (i.e. realization of iid random variable with zero mean and variance 1), and $\sigma_{t}^{2}$ is conditional variance.

The constraints $\alpha_{1} \geq 0$ and $\beta_{1} \geq 0$ are needed to ensure that $\sigma_{t}^{2}$ is strictly positive (Poon, 2005). 
In this model, the conditional mean equation is written as a function of constant, the conditional variance $\left(\sigma_{t}^{2}\right)$ as an explanatory variable, and error term. The parameter $\lambda$ is called the risk premium parameter. A positive $\lambda$ indicates that the return is positively related to its volatility. In other words, a rise in mean return is caused by an increase in conditional variance as a proxy of increased risk. The conditional mean at time $\mathrm{t}$ is denoted $E_{t}\left(\frac{r_{t}}{r_{t-1}}\right)$ or $\mu_{t}$ and the conditional variance at time $\mathrm{t}$ is denoted $V_{t}\left(\frac{r_{t}}{r_{t-1}}\right)$ or $\sigma_{t}^{2}$ (Engle 1982).

The conditional variance equation models the time varying nature of volatility of the residuals generated from the mean equation. Since $\sigma_{t}^{2}$ is the one - period ahead forecast variance based on past information, it is called the conditional variance. The conditional variance equation specified as a function of three terms: (i) A constant term: $\omega$; (ii) News about volatility from the previous period, measured as the lag of the squared residuals from the mean equation: $\varepsilon_{t-1}^{2}$ (the ARCH term); and (iii) Last period forecast variance: $\sigma_{t}^{2}$ (the GARCH term). Engle, Lilien, and Robins assume that the risk premium is an increasing function of the conditional variance of $\varepsilon_{t}$; in other words, the greater the conditional variance of returns, the greater the compensation necessary to induce the agent to hold the long - term asset Enders (2004).

\subsection{The Exponential GARCH (EGARCH) Model}

Even if the GARCH models (including GARCH-M) successfully capture the thick tail returns, and the volatility clustering, they are poor models if one wishes to capture the leverage effect since the conditional variance is a function only of the magnitudes of the past values and not their sign. In financial time-series, it has been stated that volatility behaves differently depending on if a positive or negative shock (Note 14) occurs. This asymmetric relationship is called leverage effect, and describes how a negative shock causes volatility to rise more than if a positive shock with the same magnitude had occurred. To capture this asymmetry, Nelson (1991) developed the exponential GARCH (EGARCH) model. This model captures asymmetric responses of the time-varying variance to shocks and, at the same time, ensures that the variance is always positive.

The conditional variance equation of the EGARCH $(1,1)$-M model - which will be employed in this paper - has the following specification (Note 15):

$$
\operatorname{Ln}\left(\sigma_{t}^{2}\right)=\omega+\beta_{1} \operatorname{Ln}\left(\sigma_{t-1}^{2}\right)+\alpha_{1}\left\{\left|\frac{\varepsilon_{t-1}}{\sigma_{t-1}}\right|-\sqrt{\frac{2}{\pi}}\right\}-\gamma \frac{\varepsilon_{t-1}}{\sigma_{t-1}}
$$

where $\omega, \beta_{1}, \alpha_{1}$ and $\gamma$ are constant parameters, $\operatorname{Ln}\left(\sigma_{t}^{2}\right)$ is the one-period ahead volatility forecast. This implies that the leverage effect is exponential rather than quadratic and forecast of conditional variance are guaranteed to be nonnegative, $\omega$ is the mean level, and $\operatorname{Ln}\left(\sigma_{t-1}^{2}\right)$ is the past period variance. Unlike the GARCH model, the EGARCH model allows for leverage effect. If $\gamma$ is negative, leverage effect exists. That is an unexpected drop in price (bad news) increases predictable volatility more than an unexpected increase in price (good news) of similar magnitude (Black, 1976; Christie, 1982). If $\alpha$ is positive, then the conditional volatility tends to rise (fall) when the absolute value of the standardized residuals is larger (smaller).

\section{Results}

As reported in the data description part, when the residuals were examined for heteroscedasticity, the ARCH-LM test provided strong evidence of ARCH effects in the residual series. To model this conditional heteroscedasticity, the paper proceeds by applying the GARCH-in-mean models. The results of estimating the two GARCH specifications for the two markets are presented in this section.

Beside the estimation output of the two GARCH-in-mean models, diagnostic test results for these models are also provided, in particular for testing whether there are still ARCH effects left in the residuals of the estimated models (Note 16). Table 5 shows the parameter estimates of the two GARCH models for the period under study. 
Table 5. Estimation results of the GARCH(1,1)-M and EGARCH(1,1)-M

\begin{tabular}{|c|c|c|c|c|}
\hline \multirow{2}{*}{ Coefficients } & \multicolumn{2}{|c|}{ Saudi Market } & \multicolumn{2}{|c|}{ Egyptian Market } \\
\hline & $\operatorname{GARCH}(1,1)-\mathrm{M}$ & EGARCH $(1,1)-\mathrm{M}$ & GARCH $(1,1)-\mathrm{M}$ & EGARCH $(1,1)-\mathrm{M}$ \\
\hline \multicolumn{5}{|c|}{ Conditional Mean Equation } \\
\hline$\mu$ & 0.000235 & 0.000484 & $0.001610^{*}$ & $0.000887 *$ \\
\hline$\lambda$ & 0.928367 & 0.940847 & -0.707514 & $-1.71 \mathrm{E}-05$ \\
\hline \multicolumn{5}{|c|}{ Conditional Variance Equation } \\
\hline$\omega$ & $6.79 \mathrm{E}-06^{* *}$ & $-0.602968 * *$ & $9.91 \mathrm{E}-05 * *$ & $-1.979064 * *$ \\
\hline$\alpha$ & $0.104581^{* *}$ & $0.123499 * *$ & $0.376434 * *$ & $0.382457 * *$ \\
\hline$\beta$ & $0.868009^{* *}$ & $0.848292 * *$ & $0.653892 * *$ & $0.762887 * *$ \\
\hline$\gamma$ & - & $-0.099191 * *$ & - & $-0.220823 * *$ \\
\hline$\alpha+\beta$ & 0.97259 & 0.971791 & 1.030326 & 1.145344 \\
\hline Log-Likelihood & 3750.964 & 3759.010 & 2972.531 & 2983.736 \\
\hline \multicolumn{5}{|c|}{ ARCH-LM Test for heteroscedasticity } \\
\hline Statistic & 27.01048 & 21.38055 & 1.039912 & 1.974057 \\
\hline Prob. & 0.6227 & 0.8756 & 1.0000 & 1.0000 \\
\hline
\end{tabular}

Note: ${ }^{*}$ and $* *$ denote significance at the $5 \%$ and $1 \%$ level respectively.

From the results of the variance equations reported in Tables 5, the first three coefficients $\omega$ (constant), ARCH term $(\alpha)$ and GARCH term $(\beta)$ are statistically significant and exhibit the expected sign for both markets. The significance of $\alpha$ and $\beta$ indicates that, lagged conditional variance and lagged squared disturbance have an impact on the conditional variance, in other words this means that news about volatility from the previous periods have an explanatory power on current volatility. Moreover, Table 5 shows that the sum of the two estimated ARCH and GARCH coefficients $\alpha+\beta$ (persistence coefficients) for the Egyptian market is larger than one, suggesting that the conditional variance process is explosive. However, for the Saudi market, the sum of the ARCH and GARCH coefficients is very close to one which is required to have a mean reverting variance process, indicating that volatility shocks are quite persistent, but not explosive. Furthermore, the results of asymmetric EGARCH(1,1)-M model in Table 5 indicate that the asymmetric (leverage) effect captured by the parameter estimate $\gamma$ is statistically significant with negative sign for both markets, indicating that negative shocks imply a higher next period conditional variance than positive shocks of the same magnitude, which indicates the existence of leverage effect in the returns of the two markets during the study period.

From estimation results in Table 5 , the estimated coefficient (risk premium) $(\lambda)$ of $\sigma^{2}$ in the mean equation is negative for the Egyptian market, which indicates that the mean of the return sequence negatively depends on conditional variance. This result is similar to those reached by Bekaert and Wu (2000), Breen et al. (1989), Campbell (1987), Fama and Schwert (1977), Glosten et al. (1993), and Nelson (1991) who report a negative relationship between expected return and conditional volatility. For the Saudi market, the risk premium coefficient is positive a result which is consistent with the theory of a positive risk premium on stock indices which states that higher returns are expected for assets with higher level of risk.

The ARCH-LM test statistic for all GARCH models (where ARCH and GARCH terms are taken to be of order 1) did not exhibit any additional ARCH effects remaining in the residuals of the models. This shows that the variance equations are well specified for the two markets.

\section{Conclusions and Future Directions for Research}

This paper has empirically investigated the relationship between stock market returns and volatility (risk) for the Saudi and Egyptian stock indices over the period of January 1, 2007 to December 30, 2011. The paper applied both the GARCH-M and the EGARCH-M models as originally developed by Engle (1982) and generalized by Bollerslev (1986) to check for symmetric and asymmetric (bad and good news) impact of stock price volatility on the expected returns. Based on daily closing prices of the general market index from the two markets, the empirical results of the paper provide strong evidence that daily returns can be well characterized by the GARCH approach; the returns on both markets showed a significant departure from normality and the existence of heteroscedasticity in the residuals 
series. Based on the two estimated models, the results indicate that the conditional volatility is an explosive process for Egypt while it is quite persistent for Saudi market. Furthermore, EGARCH $(1,1)-\mathrm{M}$ model shows a significant evidence for the existence of the leverage effects. The paper reports a negative relationship between expected returns and conditional volatility (risk) for Egypt and positive relation for Saudi market, a result which is consistent with the theory of a positive risk premium on stock indices which states that higher returns are expected for assets with higher level of risk. Finally, it would be interesting to further investigate the risk-return trade-off using different econometric models, for example use of multivariate GARCH-M models might give more accurate results.

\section{Acknowledgment}

The author is gratefully acknowledges the financial support provided by the Research Center at the College of Business Administration (King Saud University).

\section{References}

Andersen, T. G., \& Bollerslev, T. (1998). Answering the skeptics: Yes, standard volatility models do provide accurate forecasts. International Economic Review, 39(4), 885-905. http://dx.doi.org/10.2307/2527343

Ayub, M. (2007). Understanding Islamic Finance. Chichester, England, John Wiley \& Sons Ltd.

Bali, T. G., \& Peng, L. (2006). Is there a risk-return trade-off? Evidence from high frequency data. Journal of Applied Econometrics, 21, 1169-1198. http://dx.doi.org/10.1002/jae.911

Bansal, R., \& Lundblad, C. (2002). Market Efficiency, Fundamental Values, and Asset Returns in Global Equity Markets. Journal of Econometrics, 109, 195-237. http://dx.doi.org/10.1016/S0304-4076(02)00067-2

Bekaert, G., \& Wu, G. (2000). Asymmetric volatility and risk in equity markets. Review of Financial Studies, 13, 142. http://dx.doi.org/10.1093/rfs/13.1.1

Black, F. (1976). Studies of Stock Price Volatility Changes. In Proceedings of the 1976 Meetings of the Business and Economic Statistics Section, American Statistical Association, 177-181.

Bollerslev, T. (1986). Generalized Autoregressive Conditional Heteroscedasticity. Journal of Econometrics, 31, 307-327. http://dx.doi.org/10.1016/0304-4076(86)90063-1

Bollerslev, T., \& Wooldridge, J. M. (1992). Quasi-Maximum Likelihood Estimation and Inference in Dynamic Models with Time-Varying Covariances. Econometric Reviews, 11, 143-172. http://dx.doi.org/10.1080/07474939208800229

Breen, W., Lawrence R. G., \& Ravi J. (1989). Economic Significance of Predictable Variations in Stock Index Returns. Journal of Finance, 44, 1177-1189.

Campbell, J. Y. (1987). Stock Returns and the Term Structure. Journal of Financial Economics, 18, 373-399. http://dx.doi.org/10.1016/0304-405X(87)90045-6

Campbell, J., \& Hentschel, L. (1992). No news is good news: an asymmetric model of changing volatility in stock returns. Journal of Financial Economics, 31, 281-318. http://dx.doi.org/10.1016/0304-405X(92)90037-X

Chou, R. Y. (1988). Volatility Persistence and Stock Valuations: Some Empirical Evidence Using GARCH. Journal of Applied Econometrics, 3, 279-294. http://dx.doi.org/10.1002/jae.3950030404

Christie, A. (1982). The Stochastic Behavior of Common Stock Variances: Value, Leverage, and Interest Rate Effects. Journal of Financial Economics, 10, 407-432. http://dx.doi.org/10.1016/0304-405X(82)90018-6

El-Gamal, M. A. (2006). Islamic Finance: Law, Economics, and Practice. Cambridge: Cambridge University Press. http://dx.doi.org/10.1017/CBO9780511753756

Enders W. (2004). Applied Econometric Time Series, $2^{\text {nd }}$ Edition, Wiley Series in Probability and Statistics.

Engle R, Lilien D., \& Robins R. (1987). Estimating Time Varying Risk Premia in the Term Structure: The ARCH-M Model. Econometrica, 55, 391-407. http://dx.doi.org/10.2307/1913242

Engle, R. F. (1982). Autoregressive Conditional Heteroscedasticity with Estimates of the Variance of United Kingdom Inflation. Econometrica, 50, 987-1007. http://dx.doi.org/10.2307/1912773

Fama E. F., \& G. W. Schwert. (1977). Asset Returns and Inflation. Journal of Financial Economics, 5, 115-146. http://dx.doi.org/10.1016/0304-405X(77)90014-9

Feunou, B., Jahan-Parvar, M. R., \& Tedongap, R. (2010). Modeling Market Downside Volatility. Working Paper, Duke University, ECU, and Stockholm School of Economics, 1-63.

French, K., Schwert, W., \& Stambaugh, R. (1987). Expected stock returns and volatility. Journal of Financial 
Economics, 19, 3-29. http://dx.doi.org/10.1016/0304-405X(87)90026-2

Ghysels, E., Santa-Clara, P., \& Valkanov, R. (2005). There is a risk-return trade-off after all. Journal of Financial Economics, 76, 509-548. http://dx.doi.org/10.1016/j.jfineco.2004.03.008

Glosten, L. R., Jagannatan, R., \& Runkle, D. E. (1993). On the Relation between the Expected Value and the Volatility of the Nominal Excess Returns on Stocks. Journal of Finance, 48(5), 1779-1801.

Guo, H., \& Whitelaw, R. (2006). Uncovering the Risk-Return Relation in the Stock Market. The Journal of Finance, 61, 1433-1463. http://dx.doi.org/10.1111/j.1540-6261.2006.00877.x

Harrison, P., \& Zhang, H. (1999). An Investigation of the Risk and Return Relation at Long Horizons. Review of Economics and Statistics, 81, 1-10. http://dx.doi.org/10.1162/003465399558337

Hatemi-J A., \& Irandoust M. (2011). Dynamic Interaction between Volatility and Stock Returns in the US: Evidence from Bootstrap Causality. Research in International Business and Finance, 25(3), 329-334. http://dx.doi.org/10.1016/j.ribaf.2011.03.001

Hibbert, A. M., Daigler, R. T., \& Dupoyet, B. (2008). A behavioral explanation for the negative asymmetric return-volatility relation. Journal of Banking \& Finance, 32, 2254-2266. http://dx.doi.org/10.1016/j.jbankfin.2007.12.046

Justin, L. (2005). Modeling Derivatives in C++. Wiley Finance.

Leon, A., Nave, J., \& Rubio, G. (2007). The relationship between risk and expected return in Europe. Journal of Banking \& Finance, 31, 495-512. http://dx.doi.org/10.1016/j.jbankfin.2006.07.011

Lintner, J. (1965). The valuation of risk assets and the selection of risky investments in stock portfolios and capital budget. Review of Economics and Statistics, 47, 13-37. http://dx.doi.org/10.2307/1924119

Ludvigson, S. C., \& Ng, S. (2007). The empirical risk-return relation: A factor analysis approach. Journal of Financial Economics, 83(1), 171-222. http://dx.doi.org/10.1016/j.jfineco.2005.12.002

Mandelbrot, B. (1963). The Variation of Certain Speculative Prices. The Journal of Business of the University of Chicago, 36, 394-419.

Merton, R. (1973). An intertemporal capital asset pricing model. Econometrica, 41, 867-887. http://dx.doi.org/10.2307/1913811

Nelson, D. (1991). Conditional Heteroscedasticity in Asset Returns: a New Approach. Econometrica, 59, .347-370.

Pindyck R. (1984). Risk, Inflation and the Stock Market. American Economic Review, 74, 335-351.

Poon S. (2005). A practical guide to Forecasting financial market Volatility. Wiley Finance, England.

Poterba, J., \& Summers, L. (1986). The Persistence of Volatility and Stock Market Fluctuations. American Economic Review, 76, 1142-1151.

Rachev, S. T., Mittnik, S., Fabozzi, F. J., Focardi, S., \& Jasic, T. (2007). Financial Econometrics: From Basics to Advanced Modelling Techniques. John Willey and Sons, Inc.

Sharpe, W. F. (1964). Capital asset prices: a theory of market equilibrium under conditions of risk. Journal of Finance, 19, 425-442.

Taylor, S. J. (1986). Modeling financial time series. John Wiley \& Sons, Chichester.

Usmani, T. (1998). An Introduction to Islamic Finance. Idaratul Maarif, Karachi.

Wang P. (2003). Financial Econometrics: Methods and Models. Routledge, London and New York.

Yakob, N. A., \& Delpachitra, S. (2006). On Risk-Return Relationship: An application of GARCH(p,q)-M Model to Asia Pacific Region. International Journal of Science and Research, 2, 33-40.

\section{Notes}

Note 1. Financial markets participants are generally use stock market volatility - that is, the size of fluctuations in stock market returns - to measure stock market risk.

Note 2. This means large changes tend to be followed by large changes and small changes tend to be followed by small changes (Mandelbrot, 1963).

Note 3.This means large changes tend to be followed by large changes and small changes tend to be followed by small changes (Mandelbrot, 1963). 
Note 4. A time series is said to be heteroscedastic if its variance changes over time, otherwise it is called homoscedastic.

Note 5. The Capital Asset Pricing Model (CAPM), developed by Sharpe (1964) and Lintner (1965), is the most popular computational equation for the estimation of investment risk. CAPM argues that beta, or the systematic risk is the only relevant risk measure for investment and the relation between the returns of any asset is linearly related to its market beta.

Note 6. Since investment returns reflect the degree of risk involved with the investment, investors need to be able to determine how much of a return is appropriate for a given level of risk. This process is referred to as "pricing the risk". In order to price the risk, we must first be able to measure the risk (or quantify it) and then we must be able to decide an appropriate price for the risk we are being asked to bear.

Note 7. Merton (1973) provides the seminal work on the dynamic risk return tradeoff in equilibrium. He derives a linear relationship between the conditional mean of the return on the wealth portfolio in relation to its conditional variance and the conditional covariance with variation in the investment opportunity set,

Note 8. The Saudi Arabia Monetary Agency (SAMA) was responsible for supervising the market from 1984 until 2003. In July 2003, authority was handed over to the newly formed Capital Market Authority (CMA). The CMA is now the sole regulator and supervisor of Saudi Arabia's capital markets, and issues the necessary rules and regulations to protect investors and ensure fairness and efficiency in the market (Talat et al., 2011).

Note 9. The index was developed with a base value of 1000 in 1985 and it was restructured on 06/30/08.

Note 10. For a detailed discussion of the Egyptian Stock Market see for example, Sourial and Mecagni (1999) and Aly, et al. (2004).

Note 11. In the symmetric models, the conditional variance only depends on the magnitude, and not the sign, of the underlying asset, while in the asymmetric models the shocks of the same magnitude, positive or negative, have different effect on future volatility.

Note 12. Maximum likelihood estimator (MLE) is the most popular method where parameters are chosen such that the probability of occurrence of data under its assumed density function is the maximum. MLE is widely used because it produces an asymptotically normal and efficient parameter estimates (Justin 2005).

Note 13. Among others, Chou (1988) using a GARCH-M model found a positive relation between returns and conditional variance and also found that the GARCH-M model was more reliable than traditional econometric models such as two-stage least squares used by Pindyck (1984), and Poterba and Summers (1986).

Note 14. In macroeconomic analysis, financial markets and corporate finance, a negative shock usually implies bad news, leading to a more uncertain future. Consequently, for example, shareholders would require a higher expected return to compensate for bearing increased risk in their investment (Wang, 2003).

Note 15. The conditional mean equation remains as in the GARCH-M model (see equation 4).

Note 16. If the variance equation of GARCH model is correctly specified, there should be no ARCH effect left in the residuals. 